\title{
Multicomponent diffusion in ionic crystals: theoretical model and application to combined tracer- and interdiffusion in alkali feldspar
}

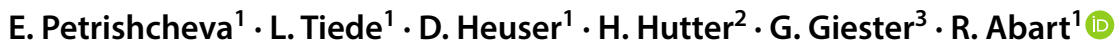

Received: 26 March 2020 / Accepted: 13 July 2020 / Published online: 31 July 2020

(c) The Author(s) 2020

\begin{abstract}
We present a model for multicomponent diffusion in ionic crystals. The model accounts for vacancy-mediated diffusion on a sub-lattice and for diffusion due to binary exchange of different ionic species without involvement of vacancies on the same sub-lattice. The diffusive flux of a specific ionic species depends on the self-diffusion coefficients, on the diffusion coefficients related to the binary exchanges, and on the site fractions of all ionic species. The model delivers explicit expressions for these dependencies, which lead to a set of coupled non-linear diffusion equations. We applied the model to diffusion of ${ }^{23} \mathrm{Na},{ }^{39} \mathrm{~K}$, and ${ }^{41} \mathrm{~K}$ in alkali feldspar. To this end, gem-quality crystals of alkali feldspar were used together with ${ }^{41} \mathrm{~K}$ doped $\mathrm{KCl}$ salt as diffusion couples, which were annealed at temperatures between $800^{\circ}$ and $950^{\circ} \mathrm{C}$. Concentration-distance data for ${ }^{23} \mathrm{Na}$, ${ }^{39} \mathrm{~K}$, and ${ }^{41} \mathrm{~K}$ were obtained by Time of Flight Secondary Ion Mass Spectrometry. Over the entire investigated temperature range the Na self-diffusion coefficient is by a factor of $\geq 500$ higher than the K self-diffusion coefficient. Diffusion mediated by binary ${ }^{39} \mathrm{~K}-{ }^{41} \mathrm{~K}$ exchange is required for obtaining satisfactory fits of the model curves to the experimental data, and the respective kinetic coefficient is well constrained.
\end{abstract}

Keywords Multicomponent diffusion · Ionic crystals · Theoretical model · Application to alkali diffusion in alkali feldspar

\section{Introduction}

Many rock-forming minerals are ionic crystals, and understanding intracrystalline diffusion in ionic crystals is of pivotal importance for interpreting composition patterns in minerals. If the initial- and boundary conditions for diffusion in a mineral are known, the duration of a geochemical perturbation or the thermal history of a rock can be inferred from the secondary compositional zoning attained during diffusion-mediated re-equilibration. Inverse diffusion modelling is at the core of geo-speedometry or diffusion chronometry (Chakraborty 2008) with numerous applications in

R. Abart

rainer.abart@univie.ac.at

1 Department of Lithospheric Research, University of Vienna, 1090 Vienna, Austria

2 Institute of Chemical Technologies and Analytics, Technical University of Vienna, 1060 Vienna, Austria

3 Institute for Mineralogy and Crystallography, University of Vienna, 1090 Vienna, Austria magmatic (Costa et al. 2008, 2010; Dohmen et al. 2017) and metamorphic (Spear and Parrish 1996) systems as well as in meteorites (Pogge von Strandmann et al. 2011). Moreover, diffusion-mediated re-equilibration may lead to the resetting of geo thermo-barometers (Carlson 2002; Kohn et al. 2016; Bussolesi et al. 2019) and of isotope chronometers (Bogard 1995; Cherniak and Watson 2001; Ito and Ganguly 2006).

For a quantitative assessment of diffusion-mediated reequilibration in minerals, it is mandatory that the underlying diffusion process is calibrated. One approach is to employ stable- or radioactive isotope tracers for determining tracer diffusion coefficients, which can then be inserted into appropriate interdiffusion models (Manning 1968). Alternatively, interdiffusion can be quantified directly from dedicated interdiffusion experiments, where two phases with different chemical compositions are used as diffusion couples (Christoffersen et al. 1983; Chakraborty and Ganguly 1992). The tracer diffusion coefficients obtained from dedicated tracer diffusion experiments are regarded to closely reflect the intrinsic mobility of the diffusing species. In contrast, in interdiffusion experiments, the diffusive fluxes of the major components are necessarily coupled (Onsager 
1931), and the analysis of interdiffusion experiments may be complicated by associated thermodynamic (Lasaga 1979) and mechanical (Larche and Cahn 1982) effects. Moreover, if the self-diffusion coefficients of the diffusing species are different, the interdiffusion coefficients are predicted to be compositionally dependent (Manning 1968). Accordingly, semi-scale solutions such as the Boltzmann-Matano method (Boltzmann 1894; Matano 1933) or the Sauer-Freise method (Sauer and Freise 1962) need to be employed for the analysis of concentration-distance data from binary interdiffusion experiments (Petrishcheva and Abart 2017). Only in special situations, effective binary diffusion coefficients were employed for a simplified treatment of interdiffusion (Chakraborty and Ganguly 1992). In the light of these complications, linking tracer- and interdiffusion coefficients determined in different experiments is generally difficult.

Recently, Belova et al. (2013, 2014, 2015) combined tracer- and interdiffusion experiments and presented an extended Boltzmann-Matano analysis by which the tracer diffusion coefficients of the different species, including their compositional dependence, can be determined. In this communication, we present an alternative approach, which is also based on the analysis of combined interdiffusion and tracer diffusion experiments. To this end, we derive a model for multicomponent diffusion in ionic crystals, which accounts for vacancy-mediated self-diffusion on a sub-lattice and for diffusion due to binary exchange of different ionic species on the same sub-lattice without the involvement of vacancies. We apply the model to the diffusion of ${ }^{23} \mathrm{Na},{ }^{39} \mathrm{~K}$, and ${ }^{41} \mathrm{~K}$ in potassium-rich alkali feldspar. The model is generally applicable to diffusion in ionic crystals that occurs by a combination of vacancy mediated diffusion and diffusion due to binary exchange. In the following, we first derive the multicomponent diffusion model and then present the results from the analysis of combined inter- and tracer diffusion experiments on alkali feldspar.

\section{Multicomponent diffusion in ionic crystals}

\section{Problem posing}

We consider multicomponent diffusion via ion migration in ionic solids. The diffusing ionic species are labeled $\alpha=1 \ldots K$. The number of ions of a particular species per unit volume is denoted as $N_{\alpha}(\mathbf{r}, t)$. The index $\alpha=0$ is reserved for vacancies. We make the following approximations:

- The ions diffuse either due to binary exchanges with each other or due to exchanges with vacancies in an otherwise fixed sub-lattice. There is only one type of vacancies.
We naturally imply that

$N_{t}=\sum_{\alpha=0}^{K} N_{\alpha}=$ const,

where $N_{t}$ is the volume density of sites in the sub-lattice.

- There are no reactions consuming or liberating ions within the crystal.

As a consequence, $K+1$ continuity equations for $N_{\alpha}(\mathbf{r}, t)$ are free of source terms, so that

$\partial_{t} N_{\alpha}+\nabla \mathbf{J}_{\alpha}=0$

where $\mathbf{J}_{\alpha}$ denotes fluxes. The total flux is assumed to vanish in the frame of reference fixed to the crystal,

$\mathbf{J}_{t}=\sum_{\alpha=0}^{K} \mathbf{J}_{\alpha}=0$

which is consistent with Eq. (1).

- The diffusion fluxes are driven by the generalized forces $\mathbf{X}_{\alpha}$ through Onsager's matrix of the transport coefficients $L_{\alpha \beta}$

$\mathbf{J}_{\alpha}=\sum_{\beta=0}^{K} L_{\alpha \beta} \mathbf{X}_{\beta}, \quad \alpha=0,1 \ldots K$.

The matrix of the transport coefficients will be specified in what follows.

For the conditions (3) and (4) to be satisfied for any set of $\mathbf{X}_{\alpha}$, the columns of $L$ must have zero sum, in which case

$\mathbf{J}_{t}=\sum_{\alpha=0}^{K}\left(\sum_{\beta=0}^{K} L_{\alpha \beta} \mathbf{X}_{\beta}\right)=\sum_{\beta=0}^{K}\left(\sum_{\alpha=0}^{K} L_{\alpha \beta}\right) \mathbf{X}_{\beta}=0$.

The reciprocal relation requires that $L_{\alpha \beta}=L_{\beta \alpha}$ implying that also the rows of $L$ have zero sum. One can then eliminate the diagonal elements of $L$ from Eq. (4) by writing

$\mathbf{J}_{\alpha}=\sum_{\beta=0}^{K} L_{\alpha \beta}\left(\mathbf{X}_{\beta}-\mathbf{X}_{\alpha}\right)$.

Each of the sub-fluxes $L_{\alpha \beta}\left(\mathbf{X}_{\beta}-\mathbf{X}_{\alpha}\right)$ is related to a binary exchange $\alpha \leftrightarrow \beta$.

- The system evolves under constant pressure and temperature.

- Making use of the fact that the frequency of $\alpha \leftrightarrow \beta$ exchanges is proportional to $N_{\alpha} N_{\beta}$, the off-diagonal elements of the Onsager matrix are modeled by the expression 


$$
L_{\alpha \beta}=-D_{\alpha \beta} \frac{N_{\alpha} N_{\beta}}{N_{t}}, \quad D_{\alpha \beta}=\text { const }, \quad \alpha \neq \beta .
$$

The coefficients $D_{\alpha \beta}$ will be related to the diffusivities in what follows. The generalized forces are related to the electrochemical potentials $\psi_{\alpha}$

$\mathbf{X}_{\alpha}=-\frac{\nabla \psi_{\alpha}}{k_{\mathrm{B}} T}, \quad \psi_{\alpha}=\mu_{\alpha}(P, T)+k_{\mathrm{B}} T \ln \frac{\gamma_{\alpha} N_{\alpha}}{N_{t}}+q_{\alpha} \phi$,

where $\mu_{\alpha}(P, T)$ is the chemical potential of a pure component, the second term appears due to the entropy of mixing, and $q_{\alpha} \phi$ is the electrostatic energy per ion. For simplicity we assume that the activity coefficient $\gamma_{\alpha}=1$ such that Eq. (7) reads

$\mathbf{X}_{\alpha}=-\frac{\nabla N_{\alpha}}{N_{\alpha}}+\frac{q_{\alpha} \mathbf{E}}{k_{\mathrm{B}} T}$,

where the electric field $\mathbf{E}=-\nabla \phi$. As to $\alpha=0, \mu_{0}$ is the free energy that is required to create a vacancy, and $q_{0}=0$.

- Charge separation, which may arise from differences in the migration rates of ions, yields some electrical field $\mathbf{E}(\mathbf{r}, t)$. The field self-organizes to inhibit further charge separation. Thereafter the system evolves in such a way that the total electric current vanishes

$$
\sum_{\alpha=1}^{K} q_{\alpha} \mathbf{J}_{\alpha}=0 .
$$

In what follows, all ions have the same charge $q$.

The above assumption has two important consequences. First, binary exchanges of two ions are not affected by the electric field because

$L_{\alpha \beta}\left(\mathbf{X}_{\beta}-\mathbf{X}_{\alpha}\right)=D_{\alpha \beta} \frac{N_{\alpha} \nabla N_{\beta}-N_{\beta} \nabla N_{\alpha}}{N_{t}}$.

If only these two components are present in some elementary volume, the sub-flux $L_{\alpha \beta}\left(\mathbf{X}_{\beta}-\mathbf{X}_{\alpha}\right)$ reduces to $-D_{\alpha \beta} \nabla N_{\alpha}$, indicating that $D_{\alpha \beta}$ is the diffusion coefficient describing diffusion due to binary $\alpha-\beta$ exchanges. Accordingly, we refer to $D_{\alpha \beta}$ as the binary diffusion coefficient. Note that the binary diffusion coefficient does not imply a specific microscopic diffusion mechanism, but refers to any process leading to the exchange of the positions of two ionic species that proceeds without a net movement of vacancies. The second consequence is that Eqs. (3) and (9), in which ion charges are taken identical, yield

$$
\mathbf{J}_{0}=0 \quad \Rightarrow \quad N_{0}=\text { const } \Rightarrow \mathbf{X}_{0}=-\frac{\nabla N_{0}}{N_{0}}+\frac{q_{0} \mathbf{E}}{k_{\mathrm{B}} T}=0 .
$$

There is no vacancy wind, because, if in an exemplary elementary volume some vacancies are filled by diffusing ions, the same number of vacancies must be freed to avoid accumulation of space charge. Writing Eq. (5) for $\alpha=0$ and making use of the fact that $\mathbf{J}_{0}$ and $\mathbf{X}_{0}$ vanish, and employing Eqs. (6) and (8), we obtain

$\sum_{\beta=1}^{K} L_{0 \beta} \mathbf{X}_{\beta}=0 \Rightarrow \sum_{\beta=1}^{K} D_{0 \beta} \frac{N_{0} N_{\beta}}{N_{t}}\left(-\frac{\nabla N_{\beta}}{N_{\beta}}+\frac{q \mathbf{E}}{k_{\mathrm{B}} T}\right)=0$,

and we derive the self-organized field

$\frac{q \mathbf{E}}{k_{\mathrm{B}} T}=\frac{\sum_{\beta=1}^{K} D_{\beta}^{*} \nabla N_{\beta}}{\sum_{\beta=1}^{K} D_{\beta}^{*} N_{\beta}}$,

where we introduced the notation

$D_{\beta}^{*}=D_{0 \beta} \frac{N_{0}}{N_{t}}$.

Therefore, the sub-flux of component $\alpha$ that results from exchanges with vacancies

$L_{\alpha 0}\left(\mathbf{X}_{0}-\mathbf{X}_{\alpha}\right)=-D_{\alpha}^{*} N_{\alpha}\left(\frac{\nabla N_{\alpha}}{N_{\alpha}}-\frac{q \mathbf{E}}{k_{\mathrm{B}} T}\right)$

reads

$L_{\alpha 0}\left(\mathbf{X}_{0}-\mathbf{X}_{\alpha}\right)=-D_{\alpha}^{*} \nabla N_{\alpha}+D_{\alpha}^{*} N_{\alpha} \frac{\sum_{\beta=1}^{K} D_{\beta}^{*} \nabla N_{\beta}}{\sum_{\beta=1}^{K} D_{\beta}^{*} N_{\beta}}$.

The first term describes self-diffusion and $D_{\alpha}^{*}$ in Eq. (10) is then recognized as the self-diffusion coefficient. The second term is related to the drift of ions in the electric field.

\section{Derivation of the diffusion model}

According to the previous section, the ion fluxes are given by

$$
\begin{aligned}
\mathbf{J}_{\alpha}= & -D_{\alpha}^{*} \nabla N_{\alpha}+D_{\alpha}^{*} N_{\alpha} \frac{\sum_{\beta=1}^{K} D_{\beta}^{*} \nabla N_{\beta}}{\sum_{\beta=1}^{K} D_{\beta}^{*} N_{\beta}} \\
& +\sum_{\beta=1}^{K} D_{\alpha \beta} \frac{N_{\alpha} \nabla N_{\beta}-N_{\beta} \nabla N_{\alpha}}{N_{t}},
\end{aligned}
$$

where the coefficient $D_{\alpha}^{*}$ refers to self-diffusion, and $D_{\alpha \beta}$ refers to the diffusion due to binary $\alpha-\beta$ exchange. It is convenient to change to the relative concentrations 
$c_{\alpha}=\frac{N_{\alpha}}{\sum_{\beta=1}^{K} N_{\beta}}=\frac{N_{\alpha}}{N_{t}-N_{0}}$,

$\mathbf{j}_{\alpha}=\frac{\mathbf{J}_{\alpha}}{N_{t}-N_{0}}, \quad \alpha=1,2, \ldots K$,

and to write Eqs. (1), (2), and (3) in the form

$\partial_{t} c_{\alpha}+\nabla \mathbf{j}_{\alpha}=0, \quad \sum_{\alpha=1}^{K} c_{\alpha}=1, \quad \sum_{\alpha=1}^{K} \mathbf{j}_{\alpha}=0$,

with

$\mathbf{j}_{\alpha}=-D_{\alpha}^{*} \nabla c_{\alpha}+D_{\alpha}^{*} c_{\alpha} \frac{\sum_{\beta=1}^{K} D_{\beta}^{*} \nabla c_{\beta}}{\sum_{\beta=1}^{K} D_{\beta}^{*} c_{\beta}}+\eta \sum_{\beta=1}^{K} D_{\alpha \beta}\left(c_{\alpha} \nabla c_{\beta}-c_{\beta} \nabla c_{\alpha}\right)$,

where it is safe to replace $\eta=\left(N_{t}-N_{0}\right) / N_{t}$ by 1 . Furthermore, it is instructive to introduce the notation

$d_{\alpha \beta}=\left(\frac{D_{\alpha}^{*} D_{\beta}^{*}}{\sum_{\gamma=1}^{K} D_{\gamma}^{*} c_{\gamma}}+D_{\alpha \beta}\right) c_{\alpha} c_{\beta}$,

cf. Eq. (6), and to write Eq. (12) in the form

$\mathbf{j}_{\alpha}=\sum_{\beta=1}^{K} d_{\alpha \beta}\left(\frac{\nabla c_{\beta}}{c_{\beta}}-\frac{\nabla c_{\alpha}}{c_{\alpha}}\right)$,

which is the most compact representation of our theory. For instance, for $K=3 \mathrm{Eq}$. (14) yields

$\left(\begin{array}{l}\mathbf{j}_{1} \\ \mathbf{j}_{2} \\ \mathbf{j}_{3}\end{array}\right)=\left(\begin{array}{ccc}-d_{12}-d_{13} & d_{12} & d_{13} \\ d_{12} & -d_{12}-d_{23} & d_{23} \\ d_{13} & d_{23} & -d_{13}-d_{23}\end{array}\right)\left(\begin{array}{l}\nabla c_{1} / c_{1} \\ \nabla c_{2} / c_{2} \\ \nabla c_{3} / c_{3}\end{array}\right)$.

Note that $\nabla c_{\alpha} / c_{\alpha}$ is the driving force for diffusion and the above matrix is subject to the reciprocal relations.

\section{Summary of the diffusion model}

For the assumptions made, the effect of vacancy-mediated self-diffusion on diffusion due to binary exchanges without the involvement of vacancies is described by the rule

$D_{\alpha \beta} \mapsto \frac{D_{\alpha}^{*} D_{\beta}^{*}}{\sum_{\gamma=1}^{K} D_{\gamma}^{*} c_{\gamma}}+D_{\alpha \beta}$.

The complicated-looking Eq. (12) for the diffusive current has Onsager's structure, c.f. Eq. (14), in terms of $\nabla c_{\alpha} / c_{\alpha}$. The off-diagonal transport coefficients $d_{\alpha \beta}$ have a universal shape (13), the modified $D_{\alpha \beta}$ is multiplied by $c_{\alpha} c_{\beta}$ in analogy with Eq. (6). The diagonal elements are obtained from the zero sum rule, like in Eq. (15). The evolution of the system is described by $K$ coupled nonlinear diffusion equations $\partial_{t} c_{\alpha}+\nabla\left[\sum_{\beta=1}^{K} d_{\alpha \beta}\left(\frac{\nabla c_{\beta}}{c_{\beta}}-\frac{\nabla c_{\alpha}}{c_{\alpha}}\right)\right]=0, \quad \alpha=1 \ldots K$,

$K-1$ of which are independent.

\section{Applications of the diffusion model}

For $K=2$ we take the first component and derive from Eq. (16) a single self-consistent nonlinear diffusion equation

$\partial_{t} c_{1}=\nabla\left[\left(\frac{D_{1}^{*} D_{2}^{*}}{D_{1}^{*} c_{1}+D_{2}^{*}\left(1-c_{1}\right)}+D_{12}\right) \nabla c_{1}\right]$.

If $D_{12}$ vanishes, we obtain Manning's expression for two coupled vacancy-mediated self-diffusion processes (Manning 1968)

For $K=3$ we take the first and the second component and reduce Eq. (16) to two coupled nonlinear diffusion equations

$\partial_{t} c_{1}=\nabla\left[\left(\frac{d_{13}}{c_{3}}+\frac{d_{12}+d_{13}}{c_{1}}\right) \nabla c_{1}+\left(\frac{d_{13}}{c_{3}}-\frac{d_{12}}{c_{2}}\right) \nabla c_{2}\right]$,
$\partial_{t} c_{2}=\nabla\left[\left(\frac{d_{23}}{c_{3}}-\frac{d_{12}}{c_{1}}\right) \nabla c_{1}+\left(\frac{d_{23}}{c_{3}}+\frac{d_{12}+d_{23}}{c_{2}}\right) \nabla c_{2}\right]$.

It is convenient to introduce a short notation for the average self-diffusion coefficient

$D_{m}^{*}=\sum_{\gamma=1}^{K} D_{\gamma}^{*} c_{\gamma}$

and to introduce diffusivities $\mathfrak{D}_{i j}$ such that

$\partial_{t} c_{i}=\sum_{j} \nabla\left(\mathfrak{D}_{i j} \nabla c_{j}\right), \quad i, j=1,2$,

where

$\mathfrak{D}_{11}=\left(\frac{D_{1}^{*} D_{2}^{*}}{D_{m}^{*}}+D_{12}\right) c_{2}+\left(\frac{D_{1}^{*} D_{3}^{*}}{D_{m}^{*}}+D_{13}\right)\left(1-c_{2}\right)$,

$\mathfrak{D}_{12}=\left(\frac{D_{1}^{*}\left(D_{3}^{*}-D_{2}^{*}\right)}{D_{m}^{*}}+D_{13}-D_{12}\right) c_{1}$,

$\mathfrak{D}_{21}=\left(\frac{D_{2}^{*}\left(D_{3}^{*}-D_{1}^{*}\right)}{D_{m}^{*}}+D_{23}-D_{12}\right) c_{2}$,

$\mathfrak{D}_{22}=\left(\frac{D_{1}^{*} D_{2}^{*}}{D_{m}^{*}}+D_{12}\right) c_{1}+\left(\frac{D_{2}^{*} D_{3}^{*}}{D_{m}^{*}}+D_{23}\right)\left(1-c_{1}\right)$.

Note that $\mathfrak{D}_{12} \neq \mathfrak{D}_{21}$. If all $D_{\alpha \beta}$ vanish, Eq. (19) reduces to the expression for ternary diffusion of Lasaga (1979), their Eq. (18a,b). The presented model quantifies vacancy-mediated diffusion of ions and, in addition, it accounts for the diffusion due to binary exchange without the involvement of vacancies. 
Let us now consider the special case, where ${ }^{23} \mathrm{Na},{ }^{39} \mathrm{~K}$, and ${ }^{41} \mathrm{~K}$ diffuse on the alkali sublattice of alkali feldspar. Experimental data for this scenario are presented and analyzed further down. When $\alpha=1,2,3$ are assigned to ${ }^{23}$ $\mathrm{Na},{ }^{39} \mathrm{~K}$, and ${ }^{41} \mathrm{~K}$, respectively, we may safely assume that $D_{2}^{*}=D_{3}^{*}$ and $D_{12}=D_{13}$, and we have

$D_{m}^{*}=D_{1}^{*} c_{1}+D_{2}^{*}\left(1-c_{1}\right)$,

and

$$
\begin{aligned}
& \mathfrak{D}_{11}=\frac{D_{1}^{*} D_{2}^{*}}{D_{m}^{*}}+D_{12}, \\
& \mathfrak{D}_{12}=0, \\
& \mathfrak{D}_{21}=\left(\frac{D_{2}^{*}\left(D_{2}^{*}-D_{1}^{*}\right)}{D_{m}^{*}}+D_{23}-D_{12}\right) c_{2}, \\
& \mathfrak{D}_{22}=\left(\frac{D_{1}^{*} D_{2}^{*}}{D_{m}^{*}}+D_{12}\right) c_{1}+\left(\frac{\left(D_{2}^{*}\right)^{2}}{D_{m}^{*}}+D_{23}\right)\left(1-c_{1}\right) .
\end{aligned}
$$

In particular, Na transport is subject to an independent selfconsistent equation

$\partial_{t} c_{1}=\nabla\left[\left(\frac{D_{1}^{*} D_{2}^{*}}{D_{1}^{*} c_{1}+D_{2}^{*}\left(1-c_{1}\right)}+D_{12}\right) \nabla c_{1}\right]$,

which can be employed to quantify $D_{1}^{*}, D_{2}^{*}$, and $D_{12}$. Thereafter the transport equation for $c_{2}$ can be used to quantify $D_{23}$. Note that, the reconstruction of the diffusivities is nontrivial. If, for instance, the concentration of $\mathrm{Na}$ is small and subject to small changes, we have

$\frac{D_{1}^{*} D_{2}^{*}}{D_{1}^{*} c_{1}+D_{2}^{*}\left(1-c_{1}\right)}+D_{12} \approx D_{1}^{*}+D_{12}$

and it would be difficult to extract all three unknown diffusivities by modeling with Eq. (23). In such a case, additional information is required for constraining all diffusivities.

\section{${ }^{23} \mathrm{Na}-{ }^{39} \mathrm{~K}-{ }^{41} \mathrm{~K}$ diffusion in sanidine}

\section{Experiment}

Single crystals of gem-quality sanidine from Volkesfeld (Eifel, Germany) with the sum formula $\left(\mathrm{K}_{0.84} \mathrm{Na}_{0.15} \mathrm{Ba}_{0.01}\right)$
$\left[\mathrm{Al}_{1.01} \mathrm{Si}_{2.99}\right]$ corresponding to Orthoclase ${ }_{84}$ Albite $_{15}$ Celsian $_{01}$ (Demtröder 2011) were used for combined tracer- and binary diffusion experiments. A representative mineral chemical analysis is given in Table 1. According to Hofmeister and Rossman (1985) sanidine from Volkesfeld has an OH content of $0.018 \mathrm{wt} \%$. The Al-Si distribution on the tetrahedrally coordinated sub-lattice of the sanidine is highly disordered, with $\Sigma t 1=0.61$. The sanidine has monoclinic symmetry with space group $\mathrm{C} 2 / \mathrm{m}$ and is homogenous down to the nanometer scale (Neusser et al. 2012). The crystals are optically clear and devoid of cracks or any other flaws. Centimetre-sized transparent sanidine crystals were oriented on a four circle single crystal $\mathrm{X}$-ray goniometer and machined to $3 \times 3 \times 2$ millimetre cuboid plates with the (001) end-faces polished with diamond paste down to $0.25 \mu \mathrm{m}$.

Whereas sodium has only one stable isotope, ${ }^{23} \mathrm{Na}$, potassium has two stable isotopes, ${ }^{39} \mathrm{~K}$, and ${ }^{41} \mathrm{~K}$ with natural abundances of 93.26 atom $\%{ }^{39} \mathrm{~K}$ and 6.73 atom $\%{ }^{41} \mathrm{~K}$. As in nature the $\mathrm{K}$ isotope fractionation between different phases is negligible, this also corresponds to the relative abundances of ${ }^{39} \mathrm{~K}$, and ${ }^{41} \mathrm{~K}$ in the original sanidine. $\mathrm{A} \mathrm{KCl}$ salt enriched in ${ }^{41} \mathrm{~K}$ with 5 atom $\%{ }^{39} \mathrm{~K}$ and 95 atom $\%{ }^{41} \mathrm{~K}$ was used as the second phase in the diffusion couple. The salt was deposited on the polished (001) end-faces of the crystal plates as a saturated aqueous $\mathrm{KCl}$ solution using a micropipette. The tracer was applied in excess to ensure constant concentration boundary conditions during the diffusion anneal. A schematic drawing of the experimental setup is shown in Fig. 1. The assemblies were dried gently to ensure that the salt residue remained on the polished surfaces of the feldspar plates. The diffusion couples were then sealed into quartz glass tubes with an inner diameter of $7 \mathrm{~mm}$ and $2 \mathrm{~mm}$

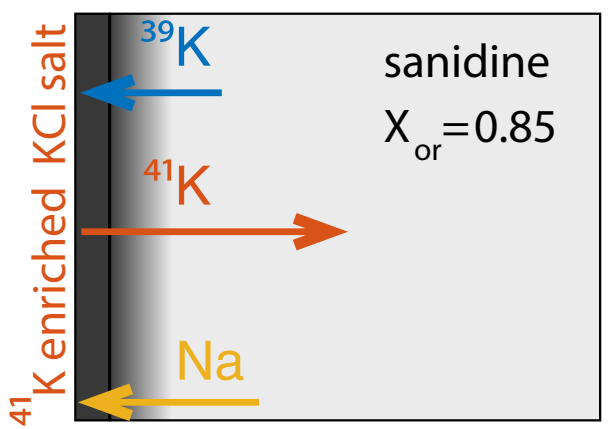

Fig. 1 Schematic drawing of experimental setup. The ${ }^{41} \mathrm{~K}$-enriched salt was applied on the polished (001) face

Table 1 Representative EPMA analysis given in wt\% oxides of sanidine from Volkesfeld, Eifel, Germany; $c_{\mathrm{K}}$ is the site fraction of $\mathrm{K}$ on the alkali sub-lattice

\begin{tabular}{lllllllllll}
\hline & $\mathrm{SiO}_{2}$ & $\mathrm{TiO}_{2}$ & $\mathrm{Al}_{2} \mathrm{O}_{3}$ & $\mathrm{FeO}$ & $\mathrm{MgO}$ & $\mathrm{CaO}$ & $\mathrm{BaO}$ & $\mathrm{Na}_{2} \mathrm{O}$ & $\mathrm{K}_{2} \mathrm{O}$ & $c_{\mathrm{K}}$ \\
\hline $\mathrm{SAN}$ & 64.30 & 0.00 & 18.56 & 0.14 & 0.00 & 0.01 & 0.55 & 1.54 & 14.47 & 0.84 \\
\hline
\end{tabular}


Table 2 Run durations and temperatures for $\mathrm{Na}-\mathrm{K}$ diffusion in sanidine perpendicular to (001)

\begin{tabular}{llllll}
\hline Temperature & $800{ }^{\circ} \mathrm{C}$ & $850{ }^{\circ} \mathrm{C}$ & $880{ }^{\circ} \mathrm{C}$ & $900{ }^{\circ} \mathrm{C}$ & $950{ }^{\circ} \mathrm{C}$ \\
\hline Run duration & $12 \mathrm{~h}$ & $4 \mathrm{~h}$ & $4 \mathrm{~h}$ & $1.5 \mathrm{~h}$ & $1 \mathrm{~h}$ \\
\hline
\end{tabular}

All experiments were done at a pressure of $\leq 1 \mathrm{bar}$

wall thickness under vacuum. Subsequently, the feldspar-salt assemblies were annealed in a muffle furnace at temperatures of 800 to $950{ }^{\circ} \mathrm{C}$ for run durations between 1 to $12 \mathrm{~h}$ (see Table 2). After annealing the samples were quenched in cold water. The tubes were opened, the feldspars were retrieved, and the salt was rinsed off with deionized water. The feldspar surfaces were shiny as before the experiment, no signs of reaction between the salt and the feldspar were detected.

The cleaned feldspar plates were analyzed for their ${ }^{39} \mathrm{~K}$, ${ }^{41} \mathrm{~K}$, and ${ }^{23} \mathrm{Na}$ concentrations using time-of-flight secondaryion-mass-spectrometry (ToF-SIMS) in depth profiling mode. With this method, the concentration of ${ }^{39} \mathrm{~K},{ }^{41} \mathrm{~K}$, and ${ }^{23} \mathrm{Na}$ could be determined to within about $0.1 \%$ of their concentration and with a depth resolution of about $10 \mathrm{~nm}$. To avoid analytical complications that may arise from deep profiles, the annealing times were chosen so that the background concentrations were reached at a profile depth of $\leq 10 \mu \mathrm{m}$. To correct for machine drift, the raw intensities were divided by the raw intensity of $\mathrm{Al}$, which can safely be assumed to have been immobile during the diffusion anneal. The relative intensities of ${ }^{39} \mathrm{~K},{ }^{41} \mathrm{~K}$, and ${ }^{23} \mathrm{Na}$ measured in the deep, unaltered portions of the crystal were then normalized to the composition of the original feldspar as obtained from EPMA analysis and natural $\mathrm{K}$-isotope abundances. The intensities were assumed to increase linearly with concentration. This assumption was proven sensible ex post by the compositions obtained from the outermost portions of the crystals, which reflected the expected equilibrium compositions with the isotopically labelled $\mathrm{KCl}$ salt.

\section{Concentration-distance data}

Given the predominance of ${ }^{39} \mathrm{~K}$ in natural alkali feldspar and the reversed relative $\mathrm{K}$ isotope abundances in the $\mathrm{KCl}$ salt, where ${ }^{41} \mathrm{~K}$ is the majority $\mathrm{K}$ isotope, the salt acted as a source for the in-diffusion of ${ }^{41} \mathrm{~K}$ from the salt into the feldspar and as a sink for ${ }^{39} \mathrm{~K}$ and ${ }^{23} \mathrm{Na}$ driving the out-diffusion of these two species from the feldspar into the salt. A typical set of ${ }^{39} \mathrm{~K},{ }^{41} \mathrm{~K}$, and ${ }^{23} \mathrm{Na}$ concentrationdistance data resulting from a diffusion anneal at $950^{\circ} \mathrm{C}$ for $1 \mathrm{~h}$ is shown in Fig. 2. Although the penetration depth is different for different experiments, depending on annealing temperature and run duration, there are several features that are common to all profiles. The concentration

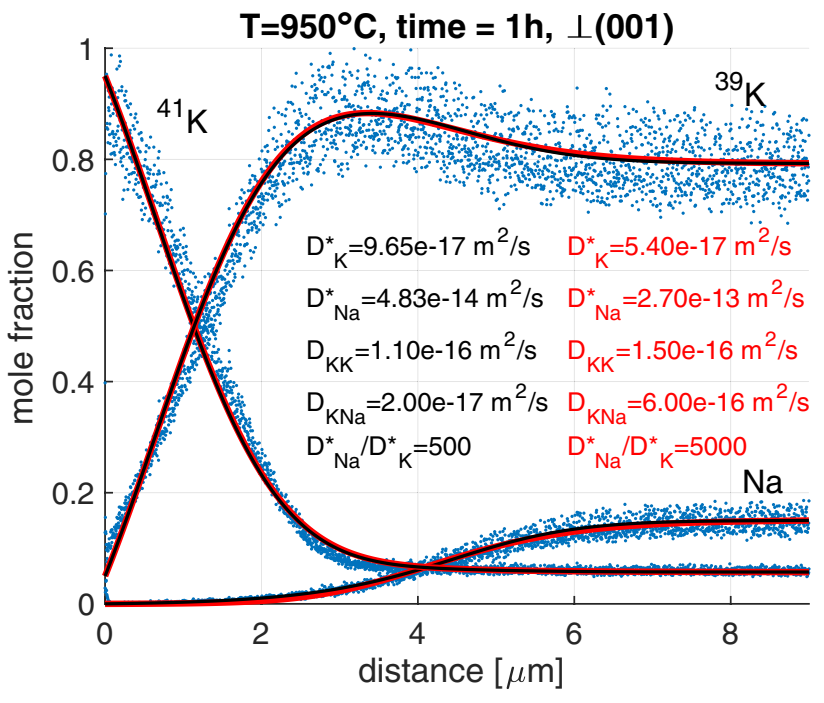

Fig. 2 Concentration-distance data of ${ }^{39} \mathrm{~K},{ }^{41} \mathrm{~K}$ and ${ }^{23} \mathrm{Na}$ along a profile taken perpendicular to (001) in Volkesfeld sanidine after a diffusion anneal at $950^{\circ} \mathrm{C}$ for $1 \mathrm{~h}$. The black and red solid lines refer to fitting of the multicomponent diffusion model accounting for vacancy-mediated diffusion and for diffusion resulting from binary exchange. The respective model parameters are indicated. Model curves producing satisfactory fits to the data are possible for a range of $D_{\mathrm{Na}}^{*} / D_{\mathrm{K}}^{*}$ diffusivity ratios. The black and red lines represent the extreme scenarios of the range of feasible $D_{\mathrm{Na}}^{*} / D_{\mathrm{K}}^{*}$ diffusivity ratios (see Fig. 3)

of ${ }^{23} \mathrm{Na}$ is 14 atom\% in the inner domains of the feldspar, which have not been affected by the cation exchange. The ${ }^{23} \mathrm{Na}$ concentration shows a smooth outwards decrease to $<0.1$ atom\%, which is the composition in equilibrium with the $\mathrm{KCl}$ salt on the surface of the crystal. The transition has a sigmoidal shape with an inflection point at about half way between the background concentration and the concentration at the surface. The transition is localized to within a few micrometers, and it is flanked by plateaus on either side, an inner plateau at the background concentration and an outer plateau at the equilibrium concentration with the salt. The ${ }^{41} \mathrm{~K}$ concentration is about 6 atom $\%$ in the original feldspar. Towards the surface, the ${ }^{41} \mathrm{~K}$ concentration is quite constant up to a position somewhat outside the inflection point of the ${ }^{23} \mathrm{Na}$ profile. Further outwards, the ${ }^{41} \mathrm{~K}$ profile steepens up over an about $1 \mu \mathrm{m}$ wide transition zone and then rises to about 95 atom $\%{ }^{41} \mathrm{~K}$ at the surface with relatively constant slope. The background concentration of ${ }^{39} \mathrm{~K}$ is about 80 atom\% in the unaltered internal portions of the feldspar and together with the 6 atom $\%{ }^{41} \mathrm{~K}$ in this domain reflects the natural relative ${ }^{41} \mathrm{~K}$ and ${ }^{39} \mathrm{~K}$ abundances. Towards the crystal surface, the ${ }^{39} \mathrm{~K}$ profile shows a peculiar maximum at a position between the inflection point of the ${ }^{23} \mathrm{Na}$ profile and the outwards steepening transition of the ${ }^{41} \mathrm{~K}$ profile. This feature can 
be understood in the light of a relatively fast out-diffusion of ${ }^{23} \mathrm{Na}$ and a comparatively slow in-diffusion of ${ }^{41} \mathrm{~K}$. In the zone where the ${ }^{23} \mathrm{Na}$ concentration has already been lowered due to the rapid out-diffusion of ${ }^{23} \mathrm{Na}$ while the ${ }^{41} \mathrm{~K}$ concentration has not yet risen due to the comparatively sluggish in-diffusion of ${ }^{41} \mathrm{~K}$, a deficiency of cations is generated on the alkali sub-lattice of the feldspar, which is compensated by the supply of ${ }^{39} \mathrm{~K}$, the locally available majority component, leading to the peculiar maximum in the ${ }^{39} \mathrm{~K}$ profile.

\section{Diffusion coefficients}

The peculiar features of the measured ${ }^{39} \mathrm{~K},{ }^{41} \mathrm{~K}$, and ${ }^{23} \mathrm{Na}$ profiles could be reproduced satisfactorily, only when, in addition to the vacancy-mediated self diffusion of ${ }^{39} \mathrm{~K}$, ${ }^{41} \mathrm{~K}$, and ${ }^{23} \mathrm{Na}$, the binary ${ }^{39} \mathrm{~K}-{ }^{41} \mathrm{~K},{ }^{39} \mathrm{~K}-{ }^{23} \mathrm{Na}$, and ${ }^{41} \mathrm{~K}-{ }^{23} \mathrm{Na}$ exchanges were considered as diffusion mechanisms. It is safe to assume that ${ }^{39} \mathrm{~K}$ and ${ }^{41} \mathrm{~K}$ have similar intrinsic mobilities, so that for the analysis of the concentration-distance data only the tracer diffusion coefficients $D_{\mathrm{Na}}^{*}$ and $D_{\mathrm{K}}^{*}$ and the binary interdiffusion coefficients $D_{\mathrm{NaK}}$ and $D_{\mathrm{KK}}$ need to be considered. The diffusion coefficients were determined by fitting numerical solutions of the coupled diffusion equations (19) to the experimental data, whereby the relations $(21,22)$ were employed. As mentioned earlier, it is difficult to constrain all diffusivities when the concentration of $\mathrm{Na}$ is low. In our experiments, $c_{\mathrm{Na}} \leq 14$ atom\%, and each measured profile can be fitted by a range of sets of diffusion coefficients. As an example, the range of diffusivities that yield satisfactory fits to the concentration-distance data for $950^{\circ} \mathrm{C} \mathrm{(Fig.} \mathrm{2)} \mathrm{is} \mathrm{illustrated} \mathrm{in} \mathrm{Fig.} \mathrm{3.} \mathrm{When} \mathrm{the} \mathrm{ratio} \mathrm{of}$ $D_{\mathrm{Na}}^{*} / D_{\mathrm{K}}^{*}$ is specified, all diffusivities can be obtained from fitting the model (19) to the experimental data. The diffusivity ratio $D_{\mathrm{Na}}^{*} / D_{\mathrm{K}}^{*}$ was thus chosen as an independent variable, and its influence on the diffusivities obtained from the fitting procedure was investigated. The main effect of increasing $D_{\mathrm{Na}}^{*} / D_{\mathrm{K}}^{*}$ is that the ${ }^{23} \mathrm{Na}$ model curve steepens around its inflection point and the transition zone between the two ${ }^{23} \mathrm{Na}$ plateaus becomes narrower. Below a value of $D_{\mathrm{Na}}^{*} / D_{\mathrm{K}}^{*}=500$, the ${ }^{23} \mathrm{Na}$ model curve becomes too flat to yield satisfactory fits to the measured profiles. This defines the lower bound for the feasible range of the $D_{\mathrm{Na}}^{*} / D_{\mathrm{K}}^{*}$ ratio. It is difficult to define an upper bound. Towards high values

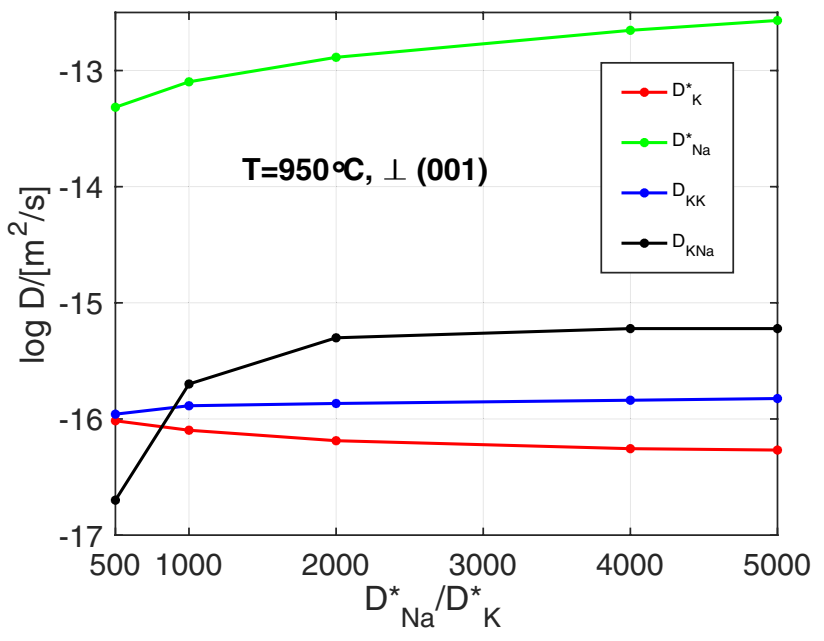

Fig. 3 Range of diffusivity sets that yield satisfactory fits to the experimental data shown in Fig. 2. The diffusivity ratio $D_{\mathrm{Na}}^{*} / D_{\mathrm{K}}^{*}$ is the only free parameter. For fixed $D_{\mathrm{Na}}^{*} / D_{\mathrm{K}}^{*}$ all diffusivities are obtained from fitting the model curves to the experimental data

of $D_{\mathrm{Na}}^{*} / D_{\mathrm{K}}^{*}$ the diffusivities obtained from fitting become successively less strongly dependent on $D_{\mathrm{Na}}^{*} / D_{\mathrm{K}}^{*}$ (Fig. 3). At diffusivity ratios in excess of about $D_{\mathrm{Na}}^{*} / D_{\mathrm{K}}^{*}=5000$, the dependence is essentially negligible for all diffusivities except for $D_{\mathrm{Na}}^{*}$, the increase of which then largely determines the increase of $D_{\mathrm{Na}}^{*} / D_{\mathrm{K}}^{*}$, while $D_{\mathrm{K}}^{*}$ and all other diffusivities remain practically constant. If the $D_{\mathrm{Na}}^{*} / D_{\mathrm{K}}^{*}$ diffusivity ratio is varied over the entire range from 500 to 5000 , the estimated values for $D_{\mathrm{K}}^{*}$ vary by a factor of $\leq 2, D_{\mathrm{Na}}^{*}$ varies by a factor of $\approx 5, D_{\mathrm{KK}}$ varies by a factor of $\leq 1.5$, and $D_{\mathrm{NaK}}$ is the least well constrained and varies by a factor of $\approx 30$. If independent information on $D_{\mathrm{Na}}^{*}$ and/or $D_{\mathrm{K}}^{*}$ is available, the remaining ambiguity can be reduced.

In Table 3 exemplary values of the diffusion coefficients obtained from applying the lower bound of the feasible range of the $D_{\mathrm{Na}}^{*} / D_{\mathrm{K}}^{*}$ diffusivity ratios are presented. We recall that a further decrease of the diffusivity ratio reproduces unsatisfactory fits to the experimental data. The diffusivity ratio may, however, be increased with the above described implications for the calculated $D_{\mathrm{K}}^{*}, D_{\mathrm{Na}}^{*}, D_{\mathrm{KK}}$, and $D_{\mathrm{NaK}}$ and still a good fit of numerics to the experiment is obtained.

The $\mathrm{Na}$ and $\mathrm{K}$ tracer diffusivities $\perp$ (001) in Volkesfeld sanidine were determined experimentally by Wilangowski et al. (2015) and by Hergemöller et al. (2017). Using their
Table 3 Diffusion coefficient for the smallest feasible $D_{\mathrm{Na}}^{*} / D_{\mathrm{K}}^{*}$ ratios

\begin{tabular}{llllll}
\hline & $800{ }^{\circ} \mathrm{C}$ & $850{ }^{\circ} \mathrm{C}$ & $880{ }^{\circ} \mathrm{C}$ & $900{ }^{\circ} \mathrm{C}$ & $950{ }^{\circ} \mathrm{C}$ \\
\hline$D_{\mathrm{K}}^{*}\left(\mathrm{~m}^{2} / \mathrm{s}\right)$ & $3.6 \times 10^{-18}$ & $1.8 \times 10^{-17}$ & $2.2 \times 10^{-17}$ & $4.0 \times 10^{-17}$ & $9.7 \times 10^{-17}$ \\
$D_{\mathrm{Na}}^{*}\left(\mathrm{~m}^{2} / \mathrm{s}\right)$ & $1.4 \times 10^{-14}$ & $1.8 \times 10^{-14}$ & $1.5 \times 10^{-14}$ & $2.0 \times 10^{-13}$ & $4.8 \times 10^{-14}$ \\
$D_{\mathrm{KK}}\left(\mathrm{m}^{2} / \mathrm{s}\right)$ & $1.0 \times 10^{-17}$ & $2.4 \times 10^{-17}$ & $6.5 \times 10^{-17}$ & $1.5 \times 10^{-16}$ & $1.1 \times 10^{-16}$ \\
$D_{\mathrm{KNa}}\left(\mathrm{m}^{2} / \mathrm{s}\right)$ & $1.0 \times 10^{-18}$ & $1.0 \times 10^{-17}$ & $2.5 \times 10^{-16}$ & $1.0 \times 10^{-17}$ & $2.0 \times 10^{-17}$ \\
\hline
\end{tabular}




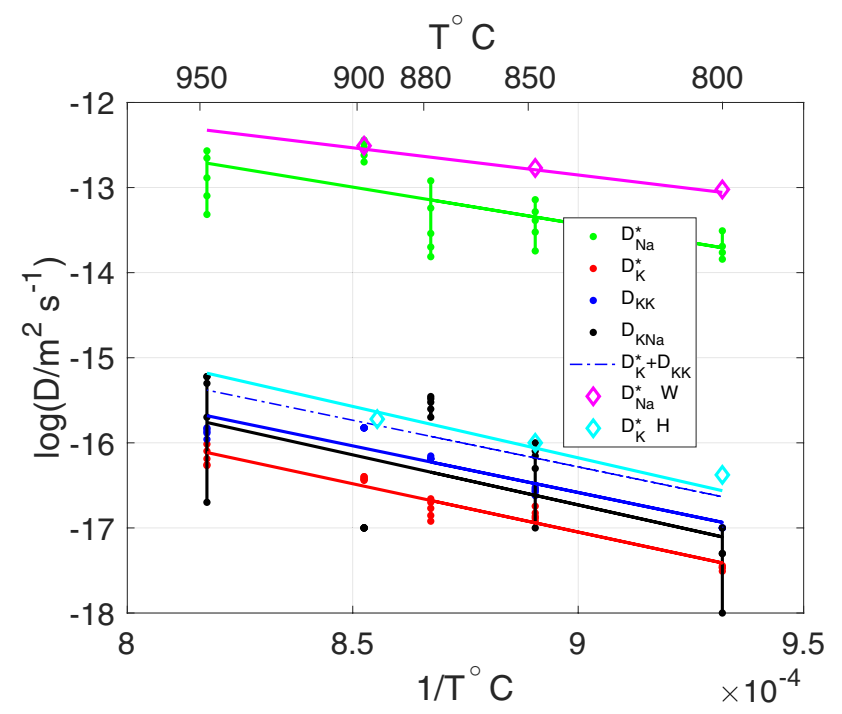

Fig. 4 Arrhenius diagram for diffusion of $\mathrm{Na}$ and $\mathrm{K} \perp$ (001). The data for $D_{\mathrm{Na}}^{*} \mathrm{~W}$ are from Wilangowski et al. (2015) and for $D_{\mathrm{K}}^{*} \mathrm{H}$ from Hergemöller et al. (2017); the different data points at a given temperature correspond to different values of $D_{\mathrm{Na}}^{*} / D_{\mathrm{K}}^{*}$ within the range of feasible diffusivity ratios

calibrations, a $D_{\mathrm{Na}}^{*} / D_{\mathrm{K}}^{*}$ of about 1000 (see Fig. 4) is calculated for a temperature of $950^{\circ} \mathrm{C}$, which is well within the parameter range shown in Fig. 3. The calibration of $D_{\mathrm{K}}^{*}$ by Hergemöller et al. (2017) is, however, rather uncertain, implying a considerable uncertainty also for the diffusivity ratio. The experimental data of Wilangowski et al. (2015) and Hergemöller et al. (2017) thus provide only weak additional constraints for the diffusivity ratio. In the absence of independent constraints on $D_{\mathrm{Na}}^{*} / D_{\mathrm{K}}^{*}$ the diffusivities can only be determined to within the range given by the lower and upper bounds of the feasible parameter range.

The temperature-dependence of the $D_{\mathrm{Na}}^{*}$ and $D_{\mathrm{K}}^{*}$ self-diffusion coefficients and of the $D_{\mathrm{NaK}}$ and $D_{\mathrm{KK}}$ binary exchange diffusion coefficients for diffusion $\perp$ (001) in the temperature range of $800^{\circ} \mathrm{C}$ to $950^{\circ} \mathrm{C}$ are shown in the Arrhenius diagram of Fig. 4. Over the entire investigated temperature range, $D_{\mathrm{Na}}^{*}$ is by a factor of about 1000 larger than $D_{\mathrm{K}}^{*}$, whereby the activation energy is somewhat larger for $\mathrm{K}$ diffusion $\left(D_{\mathrm{K}}^{0}=1.5 \times 10^{-7} \mathrm{~m}^{2} / \mathrm{s}, \mathrm{E}_{\mathrm{A}}=220 \mathrm{~kJ} / \mathrm{mol}\right)$ than for Na diffusion $\left(D_{\mathrm{Na}}^{0}=2.5 \times 10^{-6} \mathrm{~m}^{2} / \mathrm{s}, \mathrm{E}_{\mathrm{A}}=170 \mathrm{~kJ} / \mathrm{mol}\right)$. The binary exchange diffusion coefficients $D_{\mathrm{NaK}}$ and $D_{\mathrm{KK}}$ are smaller than the self-diffusion coefficients. In Fig. 4 the diffusivities obtained from our experiments are compared with the calibrations for $D_{\mathrm{Na}}^{*}$ by Wilangowski et al. (2015) and for $D_{\mathrm{K}}^{*}$ by Hergemöller et al. (2017). Despite the fact that the experimental approach used by Wilangowski et al. (2015) and by Hergemöller et al. (2017) (tracer diffusion experiments) and our study are fundamentally different, the calibrations agree quite well. To make the calibrations for potassium tracer diffusion in K-rich feldspar comparable, the effects of vacancy-mediated $\mathrm{K}$ diffusion and of the binary ${ }^{39} \mathrm{~K}-{ }^{41} \mathrm{~K}$ exchange need to be combined, yielding the dashdotted blue line in Fig. 4. The combined coefficients match very well with the calibration for $D_{\mathrm{K}}^{*}$ of Hergemöller et al. (2017), which is shown as light blue line. With respect to $D_{\mathrm{Na}}^{*}$, the agreement between our calibration and the calibration of Wilangowski et al. (2015) is somewhat less satisfactory, in that our estimate is by a factor of about 3 to 5 slower. It must be noted that Wilangowski et al. (2015) used Volkesfeld sanidine with $c_{\mathrm{K}}=0.84$, whereby $c_{\mathrm{K}}$ did not change during the experiment. In our experiments, the composition of the alkali feldspar assumes values in the range of $0.84 \leq c_{\mathrm{K}} \leq 1.00$, and the difference between our calibration and the one by Wilangowski et al. (2015) may reflect a reduced $D_{\mathrm{Na}}^{*}$ at high values of $c_{\mathrm{K}}$, a proposition that was already made by Hergemöller et al. (2017) based on Monte Carlo simulations of alkali diffusion in alkali feldspar and by El Maanaoui et al. (2016) based on measurements of ionic conductivity.

The relatively large difference between the $D_{\mathrm{Na}}^{*}$ and $D_{\mathrm{K}}^{*}$ self-diffusion coefficients and the respective activation energies has been taken as an indication for the activation of different diffusion mechanisms for $\mathrm{Na}$ and $\mathrm{K}$. Based on Monte Carlo simulations of vacancy mediated diffusion on a single sub-lattice Wilangowski et al. (2015) inferred that for the composition of Volkesfeld sanidine $D_{\mathrm{Na}}^{*} / D_{\mathrm{K}}^{*}<3.12$ irrespective of the specific atomic jump frequencies, and additional diffusion pathways such as the interstitial and the interstitialcy mechanism (Mehrer 2007) were invoked to explain the observed, substantially higher diffusivity ratio. Based on ionic conductivity measurements El Maanaoui et al. (2016) showed that in the composition range of interest the concentration of Na self-interstitials is orders of magnitude higher than the concentration of $\mathrm{K}$ self-interstitials. It was argued by Wilangowski and Stolwijk (2017) based on the relation between ionic conductivity and Na-tracer diffusion that a direct interstitial (I-I) jump mechanism of $\mathrm{Na}$ is unlikely and an indirect interstitialcy mechanism with (I-S, S-I) jumps was invoked. A contribution of interstitial Na to $\mathrm{Na}$ tracer diffusion in plagioclase was already suggested by Behrens et al. (1991). Although not explicitly formulated the binary diffusion coefficients in our model account for an interstitialcy mechanism.

Our model delivers an explicit expression for the compositional dependence of an effective $\mathrm{Na}-\mathrm{K}$ diffusion coefficient that may be defined based on Eq. (23)

$D_{\mathrm{NaK}}^{\text {eff }}=\frac{D_{\mathrm{Na}}^{*} D_{\mathrm{K}}^{*}}{D_{\mathrm{Na}}^{*} c_{\mathrm{Na}}+D_{\mathrm{K}}^{*}\left(1-c_{\mathrm{Na}}\right)}+D_{\mathrm{NaK}}$.

The compositional dependence of the effective Na-K diffusion coefficient in alkali feldspar was investigated by Petrishcheva et al. (2014) and by Schäffer et al. (2014) using a 


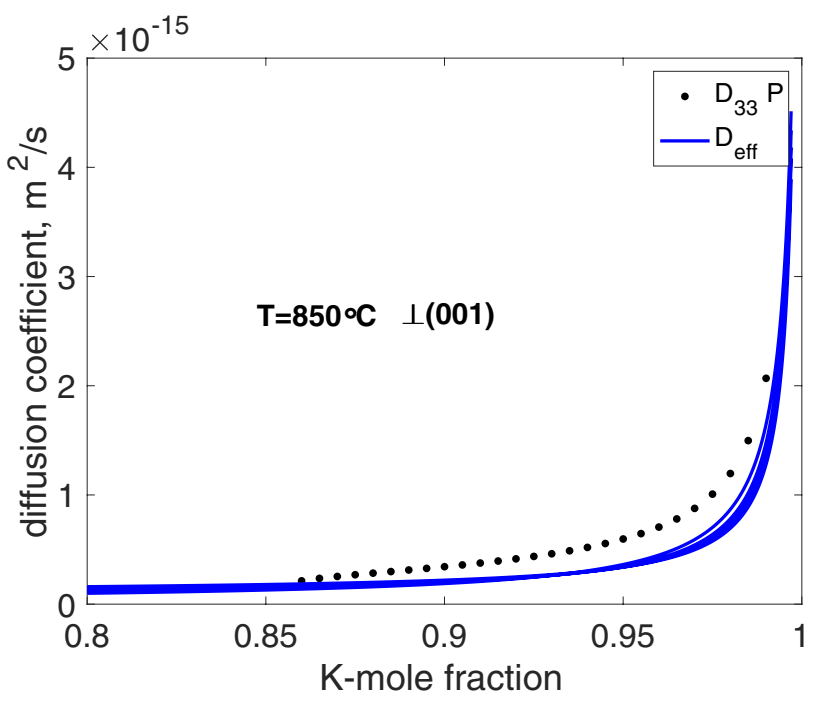

Fig. 5 Comparison of $D_{\mathrm{NaK}}^{\text {eff }}$ as obtained by Petrishcheva et al. (2014) and Schäffer et al. (2014) (dots) and our model (solid lines) in the compositional range $0.85 \leq c_{\mathrm{K}} \leq 1.0$; the different blue lines represented different values of $D_{\mathrm{Na}}^{*} / D_{\mathrm{K}}^{*}$ within the range of feasible diffusivity ratios

semi-scale solution (Boltzmann 1894) for analysing composition-distance data in an inverse approach. A comparison between the calibrations of Schäffer et al. (2014) and our analysis is presented in Fig. 5. The models agree in that an increase of the effective Na-K diffusion coefficient is predicted with increasing $c_{\mathrm{K}}$ over the entire compositional range of $0.85 \leq c_{\mathrm{K}} \leq 1.00$ that was investigated by Petrishcheva et al. (2014) and by Schäffer et al. (2014), and the absolute values of the inferred $D_{\mathrm{NaK}}^{\mathrm{eff}}$ agree to within a factor of about 2. The two models differ slightly in that the increase of $D_{\mathrm{NaK}}^{\mathrm{eff}}$ is more gradual for the predictions from the calibration of Petrishcheva et al. (2014) and Schäffer et al. (2014) than obtained from our model. We suppose that this difference is an artefact related to the different data reduction procedures applied by Petrishcheva et al. (2014) and by Schäffer et al. (2014) and the model fit used in the present study. Application of the semi-scale solution after Boltzmann (1894) requires smoothing of the raw data so that a strictly monotonically increasing/decreasing function is obtained, which can be integrated to yield meaningful compositionally dependent diffusion coefficients. The smoothing procedure tends to artificially flatten the concentration-distance curves. No such smoothing was applied in the present study, which may contribute to the observed difference.

\section{Summary and conclusions}

We derived a theoretical model for describing multicomponent diffusion in an ionic crystal. Our considerations are restricted to the case of thermodynamically ideal mixing behavior and to the migration of only homo-valent ions, and we have excluded potential mechanical effects of composition change. Within this frame, the model accounts for vacancy-mediated diffusion of ionic species and for the diffusion resulting from binary exchange of the different ionic species on the same sub-lattice without the involvement of vacancies. It is shown that the diffusive flux of an ionic species depends on its self-diffusion coefficient as well as on the self-diffusion coefficients of all other diffusing species, on the binary diffusion coefficients related to binary exchanges of ionic species without the involvement of vacancies and on all species concentrations. The model delivers an explicit expression for these dependencies and yields a set of nonlinear diffusion equations. If, in a binary case, the binary diffusion coefficients related to binary exchanges vanish, the expression reduces to Manning's expression and in the multicomponent case it reduces to Lasager's equations. The model was applied to the diffusion of ${ }^{39} \mathrm{~K},{ }^{41} \mathrm{~K}$, and ${ }^{23} \mathrm{Na}$ in alkali feldspar. From our analysis of measure ${ }^{39} \mathrm{~K},{ }^{41} \mathrm{~K}$, and ${ }^{23} \mathrm{Na}$ profiles we infer that apart from vacancy-mediated diffusion of $\mathrm{Na}$ and $\mathrm{K}$, diffusion by binary exchanges without the involvement of vacancies contributed substantially to alkali diffusion in alkali feldspar.

Acknowledgements Open access funding provided by Austrian Science Fund (FWF). This work was funded by the FWF Project P28238-N29. D.J. Cherniak, I. Villa and an anonymous reviewer are gratefully acknowledged for their thorough and constructive reviews, which substantially contributed to improving an earlier version of the manuscript.

Open Access This article is licensed under a Creative Commons Attribution 4.0 International License, which permits use, sharing, adaptation, distribution and reproduction in any medium or format, as long as you give appropriate credit to the original author(s) and the source, provide a link to the Creative Commons licence, and indicate if changes were made. The images or other third party material in this article are included in the article's Creative Commons licence, unless indicated otherwise in a credit line to the material. If material is not included in the article's Creative Commons licence and your intended use is not permitted by statutory regulation or exceeds the permitted use, you will need to obtain permission directly from the copyright holder. To view a copy of this licence, visit http://creativecommons.org/licenses/by/4.0/.

\section{References}

Behrens H, Johannes W, Schmalzried H (1991) On the mechanics of cation diffusion processes in ternary feldspars. Phys Chem Miner 17:62-78 
Belova IV, Kulkarni NS, Sohn YH, Murch GE (2013) Simultaneous measurement of tracer and interdiffusion coefficients: an isotopic phenomenological diffusion formalism for the binary alloy. Philos Mag 93:3515-3526

Belova IV, Kulkarni NS, Sohn YH, Murch GE (2014) Simultaneous tracer diffusion and interdiffusion in a sandwich-type configuration to provide the composition dependence of the tracer diffusion coefficients. Philos Mag 94:3560-3573

Belova IV, Sohn YH, Murch GE (2015) Measurement of tracer diffusion coefficients in an interdiffusion context for multicomponent alloys. Philos Mag Lett 95:416-424

Bogard D (1995) Impact ages of meteorites - a synthesis. Meteoritics 30:244-268. https://doi.org/10.1111/j.1945-5100.1995.tb01124.x

Boltzmann L (1894) Zur Integration der Diffusionsgleichung bei variablen Diffusionskoeffizienten. Annalen der Physik 53:959-964

Bussolesi M, Grieco G, Tzamos E (2019) Olivine-spinel diffusivity patterns in chromitites and dunites from the finero phlogopiteperidotite (Ivrea-Verbano Zone, Southern Alps): implications for the thermal history of the massif. Minerals 9:75. https://doi. org/10.3390/min 9020075

Carlson W (2002) Scales of disequilibrium and rates of equilibration during metamorphism. Am Mineral 87:185-204

Chakraborty S (2008) Diffusion in solid silicates: a tool to track timescales of processes comes of age. Annu Rev Earth Planet Sci 36:153-190. https://doi.org/10.1146/annurev.earth.36.03120 7.124125

Chakraborty S, Ganguly J (1992) Cation diffusion in aluminosilicate garnets-experimental-determination in spessartine-almandine diffusion couples, evaluation of effective binary diffusion-coefficients, and applications. Contrib Mineral Petrol 111:74-86. https ://doi.org/10.1007/BF00296579

Cherniak D, Watson E (2001) Pb diffusion in zircon. Chem Geol 172:5-24. https://doi.org/10.1016/S0009-2541(00)00233-3

Christoffersen R, Yund R, Tullis J (1983) Inter-diffusion of K and $\mathrm{Na}$ in alkali feldspars: diffusion couple experiments. Am Mineral 68:1126-1133

Costa F, Dohmen R, Chakraborty S (2008) Time scales of magmatic processes from modeling the zoning patterns of crystals. In: Putirka KD, Tepley FJ (eds) Minerals, inclusions and volcanic processes. Reviews in mineralogy and geochemistry, vol 69, pp 545-594. https://doi.org/10.2138/rmg.2008.69.14

Costa F, Coogan LA, Chakraborty S (2010) The time scales of magma mixing and mingling involving primitive melts and melt-mush interaction at mid-ocean ridges. Contrib Mineral Petrol 159:371387. https://doi.org/10.1007/s00410-009-0432-3

Demtröder K (2011) Untersuchung zur Al/Si-Ordnung an Sanidin Megakristallen aus der Eifel. Master thesis, Ruhr-Universität Bochum

Dohmen R, Faak K, Blundy JD (2017) Chronometry and speedometry of magmatic processes using chemical diffusion in olivine, plagioclase and pyroxenes. In: Kohn MJ, Engi M, Lanari P (eds) Petrochronology: methods and applications. Reviews in mineralogy and geochemistry, pp 535-575. https://doi.org/10.2138/ rmg.2017.83.16

El Maanaoui H, Wilangowski F, Maheshwari A, Wiemhoefer H-D, Abart R, Stolwijk NA (2016) Ionic conductivity in gem-quality single-crystal alkali feldspar from the Eifel: temperature, orientation and composition dependence. Phys Chem Miner 43:327-340

Hergemöller F, Wegner M, Deicher M, Wolf H, Brenner F, Hutter H, Abart R, Stolwijk NA (2017) Potassium self-diffusion in a K-rich single-crystal alkali feldspar. Phys Chem Miner 44:345-351. https ://doi.org/10.1007/s00269-016-0862-1

Hofmeister A, Rossman G (1985) A model for the irradiative coloration of smoky feldspar and the inhibiting influence of water. Phys Chem Miner 12:324-332. https://doi.org/10.1007/BF00654342

Ito M, Ganguly J (2006) Diffusion kinetics of $\mathrm{Cr}$ in olivine and Mn-53-Cr-53 thermochronology of early solar system objects.
Geochim Cosmochim Acta 70:799-809. https://doi.org/10.1016/j. gca.2005.09.020

Kohn MJ, Penniston-Dorland SC, Ferreira JCS (2016) Implications of near-rim compositional zoning in rutile for geothermometry, geospeedometry, and trace element equilibration. Contrib Mineral Petrol 171:78. https://doi.org/10.1007/s00410-016-1285-1

Larche F, Cahn J (1982) The effect of self-stress on diffusion in solids. Acta Met 30:1335-1345

Lasaga A (1979) Multicomponent exchange and diffusion in silicates. Geochim Cosmochim Acta 43(4):455-469. ISSN:0016-7037. https://doi.org/10.1016/0016-7037(79)90158-3

Manning J (1968) Diffusion kinetics for atoms in crystals. Princeton, Van Norstrand

Matano C (1933) On the relation between the diffusion-coefficients and concentrations of solid metals (the nickel-copper system). Jpn J Phys 8:109-113

Mehrer H (2007) Diffusion in solids-fundamentals, methods, materials, diffusion-controlled processes. Springer, Berlin

Neusser G, Abart R, Fischer F-D, Harlov D, Norberg N (2012) Experimental $\mathrm{Na} / \mathrm{K}$ exchange between alkali feldspar and an $\mathrm{NaCl}-\mathrm{KCl}$ salt melt: chemically induced fracturing and element partitioning. Contrib Mineral Petrol 164:341-358

Onsager L (1931) Reciprocal relations in irreversible processes. I. Phys Rev 37:405-426

Petrishcheva E, Abart R (2017) Diffusion: some mathematical foundations and applications in mineralogy. In: Heinrich W, Abart R (eds) Mineral reaction kinetics: microstructures, textures, chemi$\mathrm{cal}$ and isotopic signatures. European mineralogical union notes in mineralogy, vol 16, pp 255-294. https://doi.org/10.1180/EMUnotes.16.9

Petrishcheva E, Abart R, Schäffer A-K, Habler G, Rhede D (2014) Sodium-potassium interdiffusion in potassium-rich alkali feldspar I: full diffusivity tensor at $850^{\circ} \mathrm{C}$. Am J Sci 314(9):1284-1299

Pogge von Strandmann PAE, Elliott T, Marschall HR, Coath C, Lai Y-J, Jeffcoate AB, Ionov DA (2011) Variations of Li and $\mathrm{Mg}$ isotope ratios in bulk chondrites and mantle xenoliths. Geochim Cosmochim Acta 75:5247-5268. https://doi.org/10.1016/j. gca.2011.06.026

Sauer F, Freise V (1962) Diffusion in binären gemischen mit volumenänderung. Zeitschrift für Elektrochemie 66:353-362

Schäffer A-K, Petrishcheva E, Habler G, Abart R, Rhede D, Giester G (2014) Sodium-potassium interdiffusion in potassium-rich alkali feldspar II: composition- and temperature-dependence obtained from cation exchange experiments. Am J Sci 314:1300-1318

Spear F, Parrish R (1996) Petrology and cooling rates of the Valhalla complex, British Columbia, Canada. J Petrol 37:733-765. https ://doi.org/10.1093/petrology/37.4.733

Wilangowski F, Stolwijk NA (2017) A Monte Carlo study of ionic transport in a simple cubic random alloy via the interstitialcy mechanism: effects of non-collinear and direct interstitial jumps. Philos Mag 97:108-127. https://doi.org/10.1080/14786 435.2016.1235293

Wilangowski F, Divinski S, Abart R, Stolwijk NA (2015) Radiotracer experiments and Monte Carlo simulation of sodium diffusion in alkali feldspar: evidence against the vacancy mechanism. Defects Diffus Forum 363:79-84. https://doi.org/10.4028/www.scientific .net/DDF.363.79

Publisher's Note Springer Nature remains neutral with regard to jurisdictional claims in published maps and institutional affiliations. 